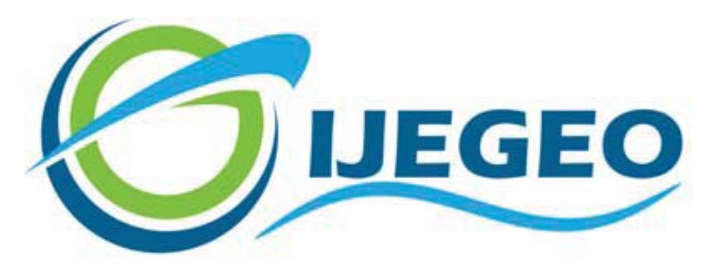

International Journal of Environment and Geoinformatics (IJEGEO) is an international, multidisciplinary, peer reviewed, open access journal.

\title{
Determination of Land Use Change using Support Vector Machines: A Case Study of Arnavutkoy, Istanbul
}

\section{Hatice ÇATAL REİS, Gülsena YILANCI}

\author{
Chief in Editor \\ Prof. Dr. Cem Gazioğlu \\ Co-Editors \\ Prof. Dr. Dursun Zafer Şeker, Prof. Dr. Şinasi Kaya, \\ Prof. Dr. Ayşegül Tanık and Assist. Prof. Dr. Volkan Demir
}

Editorial Committee (September 2021)

Assoc. Prof. Dr. Abdullah Aksu (TR), Assit. Prof. Dr. Uğur Algancı (TR), Prof. Dr. Bedri Alpar (TR), Assoc. Prof. Dr. Aslı Aslan (US), Prof. Dr. Levent Bat (TR), Prof. Dr. Paul Bates (UK), İrşad Bayırhan (TR), Prof. Dr. Bülent Bayram (TR), Prof. Dr. Luis M. Botana (ES), Prof. Dr. Nuray Çağlar (TR), Prof. Dr. Sukanta Dash (IN), Dr. Soofia T. Elias (UK), Prof. Dr. A. Evren Erginal (TR), Assoc. Prof. Dr. Cüneyt Erenoğlu (TR), Dr. Dieter Fritsch (DE), Prof. Dr. Çiğdem Göksel (TR), Prof.Dr. Lena Halounova (CZ), Prof. Dr. Manik Kalubarme (IN), Dr. Hakan Kaya (TR), Assist. Prof. Dr. Serkan Kükrer (TR), Assoc. Prof. Dr. Maged Marghany (MY), Prof. Dr. Michael Meadows (ZA), Prof. Dr. Nebiye Musaoğlu (TR), Prof. Dr. Masafumi Nakagawa (JP), Prof. Dr. Hasan Özdemir (TR), Prof. Dr. Chryssy Potsiou (GR), Prof. Dr. Erol Sarı (TR), Prof. Dr. Maria Paradiso (IT), Prof. Dr. Petros Patias (GR), Prof. Dr. Elif Sertel (TR), Prof. Dr. Nüket Sivri (TR), Prof. Dr. Füsun Balık Şanlı (TR), Prof. Dr. Uğur Şanlı (TR), Duygu Ülker (TR), Prof. Dr. Seyfettin Taş (TR), Assoc. Prof. Dr. Ömer Suat Taşkın (TR), Assist. Prof. Dr. Tuba Ünsal (TR), Dr. Manousos Valyrakis (UK), Dr. İnese Varna (LV), Dr. Petra Visser (NL), Prof. Dr. Selma Ünlü (TR), Assoc. Prof. Dr. Oral Yağcı (TR), Prof. Dr. Murat Yakar (TR), Assoc. Prof. Dr. İ. Noyan Yılmaz (AU); Assit. Prof. Dr. Sibel Zeki (TR)

Abstracting and Indexing: TR DIZIN, DOAJ, Index Copernicus, OAJI, Scientific Indexing Services, International Scientific Indexing, Journal Factor, Google Scholar, Ulrich's Periodicals Directory, WorldCat, DRJI, ResearchBib, SOBIAD 
Dear colleagues and friends,

International Symposium on Applied Geoinformatics (ISAG2019) was held in Istanbul on 7-9 November 2019. The symposium is organized with the aim of promoting the advancements to explore the latest scientific and technological developments and opportunities in the field of Geoinformatics.

The symposium was jointly organized by the Department of Geomatics Engineering, Yıldız Technical University, Istanbul, Turkey and the Institute of Geodesy and Geoinformatics, University of Latvia, RigaLatvia.

Our main aim was to bring researchers to share knowledge and their expertise about state-of-art developments in the field of Geoinformatics. We wish to discuss the latest developments, opportunities and challenges that can help the Geoinformatics community to solve many real-world challenges. Although this forum is initiated by two countries, Turkey and Latvia, it has a global perspective to promote technologies and advancements that would help us live in a better world.

290 participants and scientists from 27 countries were attended to the ISAG2019. 118 oral and 16 poster presentations were presented by 45 international and 89 Turkish presenters in 29 sessions between 7-9 November 2019.

We are much thankful to our supporting institutions Turkish General Directorate of Mapping, The Embassy of Latvia in Turkey, General Directorate of Geographical Information Systems/Turkey, Fatih Municipality.

The presentation "XXX" was presented at the ISAG2019 and was proposed by our scientific committee for evaluation in the International Journal of Environmental and Geoinformatics (IJEGEO).

The next ISAG symposium will be organized in Riga, Latvia on 16-17 November 2021. I do really hope to see you all in Latvia at the $2^{\text {nd }}$ ISAG Symposium.

On behalf of ISAG-2019 Organization Committee

Conference Chair

Prof. Dr. Bülent Bayram

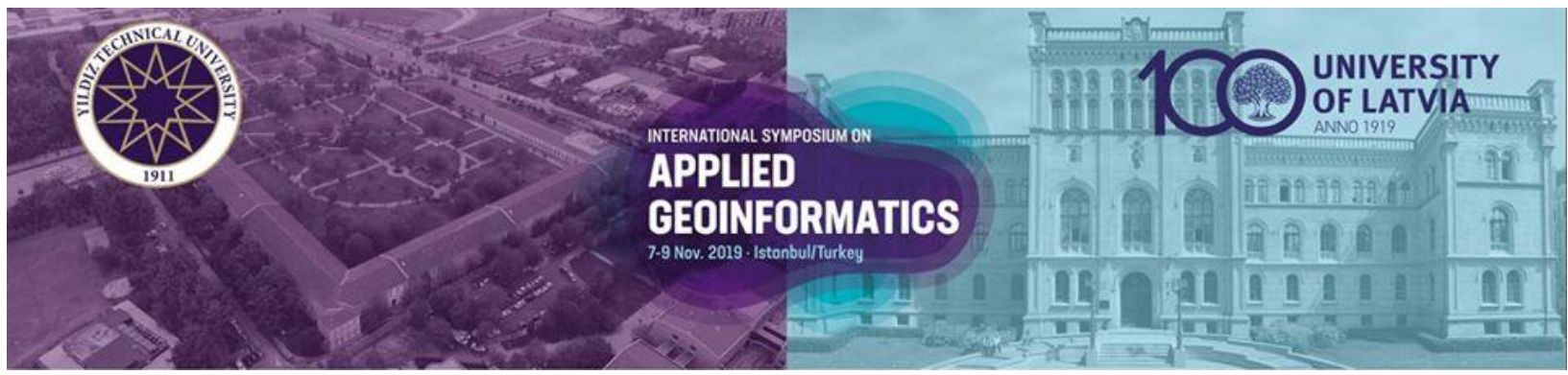




\title{
Determination of Land Use Change using Support Vector Machines: A Case Study of Arnavutkoy, Istanbul
}

\author{
Hatice Çatal Reis * iD, Gülsena Yilanci \\ Department of Geomatics Engineering, Gumushane University, 29100, Baglarbasi, Gumushane, Turkey. \\ * Corresponding author: H. Çatal-Reis \\ * E-mail: hatice.catal@yahoo.com.tr
}

Received 13 Feb 2020

Accepted 10 Feb 2021

How to cite: Reis and Yilanci (2021). Determination of Land Use Change using Support Vector Machines: A Case Study of Arnavutkoy, Istanbul, International Journal of Environment and Geoinformatics (IJEGEO), 8(3):256-266. doi. 10.30897/ijegeo.ijegeo.688826

\begin{abstract}
As a result of the development of cities and inclination towards urbanization, natural areas decreased while urban areas increased. In this respect, determination of impermeable surfaces is important for the problems covering; effects of urbanization on natural environment, global environmental variation, urban atmospheric process, human activities and the effects of urbanization on the environment. Remote sensing images are used to examine and classify land cover/uses. Traditional classification methods are mainly divided into supervised classification and unsupervised classification. The aim of this study is to classify land cover/use and to state temporal change using the Support Vector Machines (SVM) approach, which is a supervised classification method. Arnavutkoy district of Istanbul was chosen as the study area for land use and change detection analysis. Landsat 5/7/8 satellite images of Arnavutkoy district were obtained and SVM process was applied to obtain these images. Firstly, four classes were created for each image: urban areas, vegetation, bare soils and wetlands SVM was applied and accuracy analysis was performed to the images classes of which were created before. CAD software and GIS software were used for image processing. The classification accuracy for SVM was found to be $98.66 \%, 98.31 \%, 98.95 \%, 97.99 \%, 96.37 \%, 97.90 \%$ (from 1995 to 2019). In addition, ROC analysis was used for comparison of accuracy analysis. As a result of this study, land cover/use change of Arnavutkoy district in the last 20 years has been determined. The urban area of the district was $40.99 \mathrm{~km}^{2}$ in 1995 and $93.76 \mathrm{~km}^{2}$ in 2019. In addition, the impact of the Europe's largest airport on land cover / use has been examined. The results showed that the accuracy of using SVM to classify land use/cover is high. Therefore, it has been proposed that this algorithm is used as an optimal classifier for land use/cover maps.
\end{abstract}

Keywords: Support Vector Machine, Classification, Remote Sensing, Landsat

\section{Introduction}

Land cover/use information is required in many applications performed today. In this regard, remote sensing provides an important source of data and information to applications. The "Classification" method is a widely used approach for the extraction of information from satellite imagery and the production of land cover/use maps (Mathur et al., 2008; Petropoulos et al., 2012a). The purpose of the classification is to divide all pixels in the satellite image into different groups according to their spectral characteristics and to assign the pixels to clusters of land cover classes according to their reflectance values (Foody, 2002; Kavzoglu and Colkesen, 2009). There are two main approaches in the classification, supervised and unsupervised. Supervised classification is used more often due to its high accuracy and reliability (Kavzoglu and Colkesen, 2010). Nonparametric classification methods such as decision tree (Nagel Yuan, 2016; (Zhang et al., 2018), support vector machines (Kavzoglu and Colkesen, 2009; Zhang et al., 2018; Karimi et al., 2019) and artificial neural networks (Hu and Weng, 2009; Mohapatra and Wu, 2010) can be used to classify remotely sensed images (Lu, et al., 2007; Çelik and Gazioğlu, 2020; Tonbul and Kavzoğlu, 2020; Erdem and Avdan; 2020; Ozturk et al., 2020; Karagöl et al., 2020).
There are many studies on SVM in the literature: The researchers investigated the applicability of SVM in the classification of hyperspectral images to detect land cover change (Nemmour and Chibani, 2006). They performed SVM-based change detection to map urban growth and compared it to artificial neural networks to support experimental analysis. In the results, they found that SVMs perform better on accuracy and generalization. It has been made land cover classification by applying SVM to Landsat ETM+ and Terra ASTER images (Kavzoglu and Colkesen, 2009). In the classification of data sets, they applied the functions of polynomial and radial basis kernels with estimated optimum parameters and analyzed the results. They determined that the classification accuracy of SVMs, in which the radial basic function kernel was used, performed better than the maximum probability classifier. In the study, Hyperion hyperspectral images by applying Support Vector Machines (SVMs) and Artificial Neural Networks (ANN) classification methods for land cover classification was analyzed (Petropoulos et al., 2012b). Although the results show that the two classifiers produce close accuracy, SVMs produced better results and explained the spatial distribution of land cover better. The study has been investigating the methodology and results of 
classification of Istanbul's Landsat TM data for 1987 and 2007 (Buyuksalih, 2016). The classification accuracy was found as $79 \%$ for 1987 and $83.50 \%$ for 2007 . Classifications were found to be an economical and accurate way to measure, map and analyze land cover changes over time. Bulut Gunlu (2016) tried to determine the most suitable technique by classifying land use classes with different controlled classification algorithms using Landsat 8 satellite images. Best results of the highest probability method was compared to the results of SVM polynomial function. The values for the highest probability method are 0.81 and $85 \%$. Values for SVM polynomial function were found 0.79 and $84 \%$, respectively. According to the results obtained, they found that the highest probability method correctly classifies $47.5 \%$ of the total area and $43.3 \%$ with the SVM polynomial function. The researcher classified the WorldView-2 multi-band image with advanced classification algorithms such as Support Vector Machines (SVM), k-Nearest Neighbor (kNN) and Artificial Neural Network (ANN) to produce land cover maps (Serifoglu Yilmaz et al., 2018). They evaluated the accuracy with randomly selected control points. They found that the SVM algorithm classifies images with the best classification accuracy of $72.38 \%$. (Karimi et al., 2019), they reviewed SVM to improve the quality of the urban expansion forecast. The binary SVM model they developed selects the most appropriate kernel function by editing the penalty parameter and determines the best value for the parameter of the kernel function. In the study, they obtained $98 \%$ education accuracy and $85 \%$ test accuracy. In another study conducted a study with SVM using Landsat imagery obtained between 1995 and 2015 to examine land cover and land cover changes on the ecological region of Lake Uvs. In the results, they found that the Uvs Lake Basin has deteriorated over the last twenty years due to factors such as global warming, drought, human activities, and wind erosion (Jamsran et al., 2019). In the study, explored the use of multi-time Polarimetric SAR images in the classification of agricultural products. In the study, they used light gradient acceleration machines (LightGBM), random forest (RF) and support vector machines (SVM) to classify five different products (corn, potatoes, wheat,

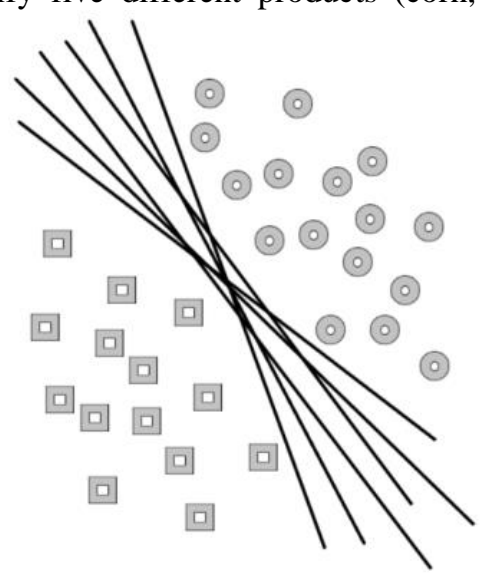

sunflower and forage crops). They calculated the accuracy values of the classifications as $0.857( \pm 0.026)$, $0.855( \pm 0.033)$ and $0.834( \pm 0.039)$ for LightGBM, RF and SVM algorithms, respectively (Ustuner Balik Sanli, 2020).

As it is seen in the literature research, the use of SVM in land use/cover classification provides high accuracy in the results. Istanbul Airport, the construction of which started in 2014 in Arnavutkoy, is currently the largest airport in Europe. There is no such detailed study in literature for this region of Istanbul. For this reason, it is aimed to determine the change of land cover/use in the last 20 years in the district of Arnavutkoy, which has been chosen as the study area and to examine the effect of Istanbul Airport on this change. SVM, the supervised classification method for change detection, was selected and the increase in the urban area was successfully detected during the period from 1995 to 2019.

The article consists of 5 steps. Classification methods of images remotely perceived in step 1 , the purpose of the study and literature research; Step 2, SVM and its mathematical infrastructure, the advantages of SVM and the properties of Landsat satellite; step 3 the application area, materials used and application steps; There are conclusions and recommendations in step 4 and bibliography step 5 .

\section{Material and Method}

Controlled classification, which is one of the classification methods, is widely used in obtaining land cover/usage information from remote sensing data (Mathur et al., 2008). In this study, the temporal change of the land surface of Arnavutkoy was determined by SVM.

\section{Support Vector Machines (SVM)}

The support vector machines (SVM) method is a nonparametric classification algorithm based on statistical learning theory developed for classification or regression problems by Vladimir Vapnik et al. (Vapnik, 1995).

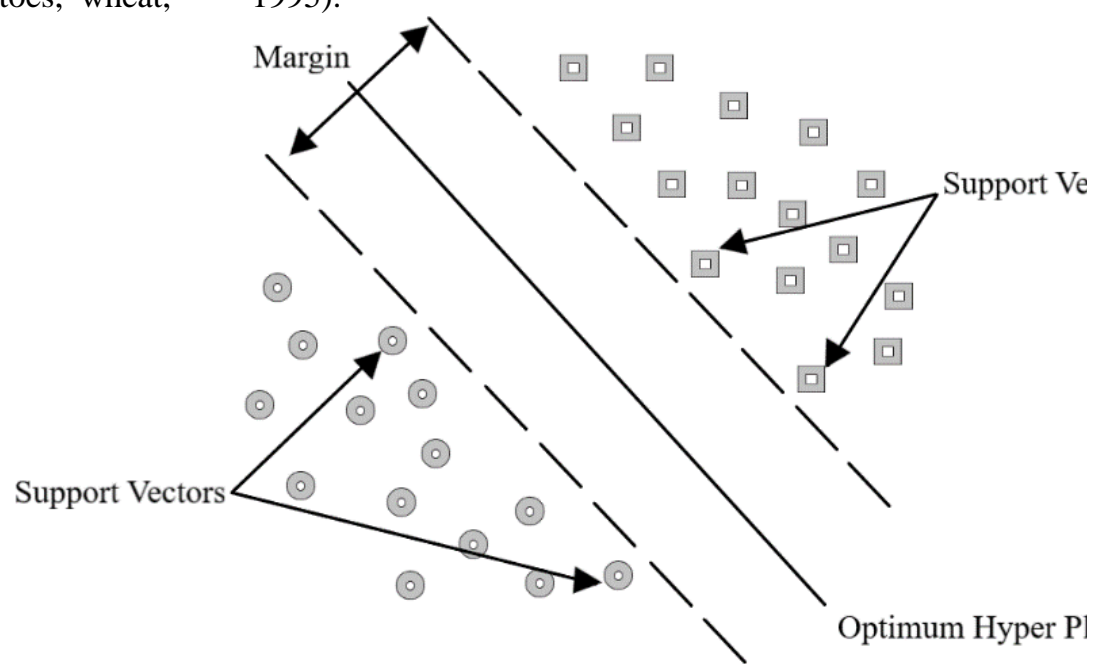

Figure 1. Hyper planes for linearly separable data (a), Optimum hyper plane and support vectors (b) (Kavzoglu and Colkesen, 2009). 
This method is used in many areas such as object recognition (face recognition, fingerprint recognition etc.), handwriting identification, text classifications (Joachims, 1998; Heisele et al., 2003; Liu et al., 2003; Hong et al., 2008). SVM; it is a machine learning based on the principle of predicting and generalizing other data by taking an example from a training data (Kavzoglu Colkesen, 2009; Song et al., 2012). Initially aimed at classifying two-class linear data, SVM was developed for the classification of multi-class and non-linear data since it would be insufficient for problems on the surface of the world (Cortes et al., 1995; Mathur et al., 2008).
This method, which separates the data of two classes, aims to determine the best decision function (hyperplane) in order to make an effective classification (Vapnik, 2000). What important in classification of data with two classes is the determination of the hyperplanes that make the most effective separation from the infinite grain planes that provide the classification (Fig.1a, Fig.1b). While determining these hyperplanes, using the structural risk minimization principle, the boundary distance between the two hyperplanes is maximized (Vapnik, 1995; Huang et al., 2002).
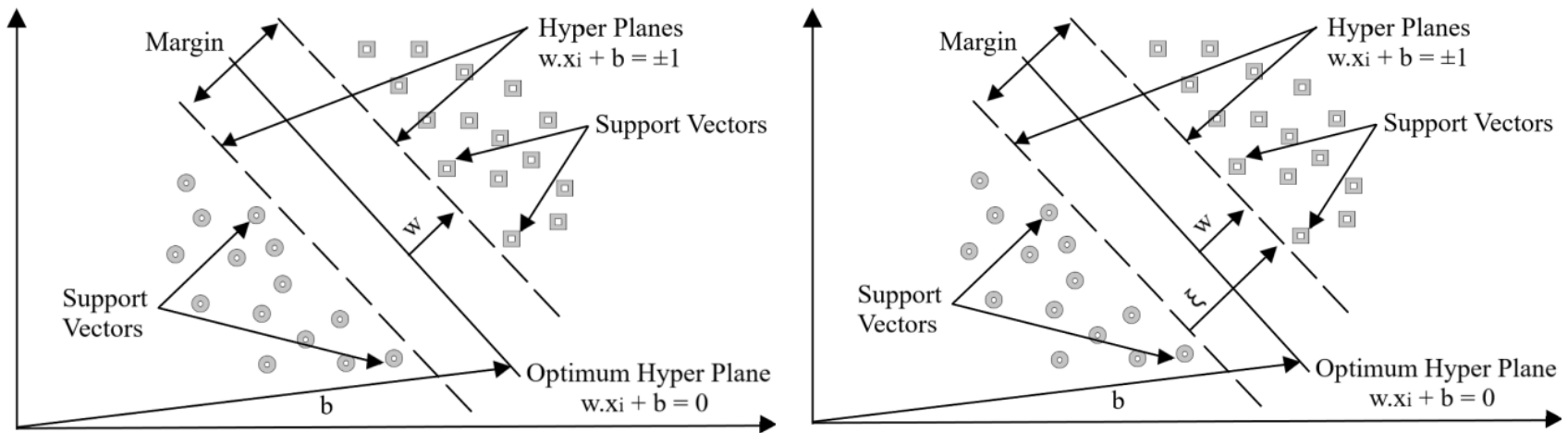

Figure 2. Linearly separable SVM (a), SVM that cannot be separated linearly (b) (Kavzoglu and Colkesen, 2009)

\section{Linear separable SVM}

It is the situation where the two classes, which are in a linearly distributed state, can be separated from each other with the help of a decision function obtained using training data. An educational data set containing $\mathrm{N}$ samples $\left\{x_{i}, y_{i}\right\}(i=1, \ldots, n)$ can be classified by creating class labels in the form of $y €\{-1,+1\}$. Here $x € \mathrm{R}^{\mathrm{N}}$ and represents a $\mathrm{N}$ dimensional space (Osuna et al., 1997; Huang et al., 2002; Son et al., 2012). A hyper plane w. $x_{i}+b=0$ is shown (Melgani Bruzzone, 2004). For linearly divisible data with two classes, hyperplanes

w. $x_{i}+b \geq+1$ for all $y=+1$

w. $x_{i}+b \geq-1$ for all $y=-1$

is expressed as (Karimi et al., 2019). Here $x_{i}$ shows the point in the hyper plane, $w$ is the normal of the hyper plane (weight vector) and $\mathrm{b}$ is the distance (trend value) from the starting point of the hyper plane (Cortes Vapnik, 1995; Huang et al., 2002). If Equation 1 and Equation 2 are converted to a single equation

$\mathrm{y}_{\mathrm{i}}\left(\mathrm{w} . \mathrm{x}_{\mathrm{i}}+\mathrm{b}\right)-1 \geq 0, \mathrm{x}_{\mathrm{i}} €\{-1,+1\}$ and $\mathrm{i}=1, \ldots, \mathrm{n}$

\section{is expressed as (Cortes Vapnik, 1995).}

In this case, the hypothesis space can be defined as $\mathrm{f}_{\mathrm{w}, \mathrm{b}}$ $=\operatorname{sign}(w . x+b)$ (Osuna et al., 1997). As seen in Figure $2 \mathrm{a}$, the limit width (margin) of the hyperplanes determined by limiting to the optimum hyper plane and limited by the support vector points is expressed as $2 /\|w\|$ (Song et al., 2012). The best hyperplane that makes maximum limitations in linearly separable data is the plane where $\|\mathrm{w}\|^{2}$ is minimum (Song et al., 2012). This statement, adhering to Equation 3

$\min \left[\frac{1}{2}\|\mathrm{w}\|^{2}\right]$

is minimized and optimum plane is obtained (Osuna et al., 1997). For the solution of Equation 4, the decision function using Lagrange functions

$f(x)=\operatorname{sign}\left(\sum_{i=1}^{n} \lambda_{i} \cdot y_{i}\left(x \cdot x_{i}\right)+b\right)$

is expressed as (Osuna et al., 1997).

Here; $\mathrm{n}$ represents the number of support vectors, $\lambda_{\mathrm{i}}$ positive Lanrange multipliers, y class labels, $\mathrm{x} N$ dimensional space, $b$ trend value.

\section{Linear inseparable SVM}

In the classification of satellite images, a nonlinear line is required to make the classification (Fig.3).

As shown in Figure 2b, the solution of the linear fragmentation problem can be done by adding an artificial variable to Equation 3 (Cortes et al., 1995; Huang et al., 2002). $\xi$ (slack) takes positive values and expresses classification errors (Kavzoglu and Colkesen, 2009). If Equality 3 is rearranged

$y_{i}\left(w . x_{i}+b\right)-1+\xi_{i} \geq 0$

is obtained in the form of.

In cases where linear separation cannot be made, the SVM algorithm works with a $\mathrm{C}$ editing parameter that is 
within the range $(0<\mathrm{C}<\infty)$ that maximizes the boundary and minimizes erroneous classifications. (Cortes and Vapnik, 1995). In such a case, C $\sum_{\mathrm{i}=1}^{\mathrm{n}} \xi_{\mathrm{i}}$ must be added to Equation 4. In this way, if $\xi_{i}$ takes large values, the minimum condition $(1 / 2)\|w\|^{2}$ is

$$
\min \left[\frac{1}{2}\|\mathrm{w}\|^{2}+\mathrm{C} \sum_{\mathrm{i}=1}^{\mathrm{n}} \xi_{\mathrm{i}}\right]
$$
applied to the solutions (Kavzoglu and Colkesen, 2009). Optimization problem of nonlinear data

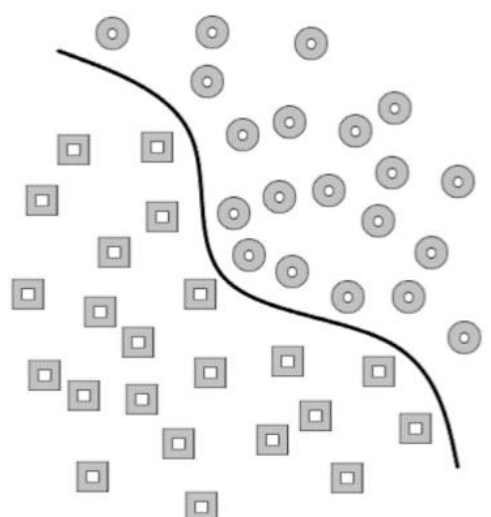

Figure 3. Two classes that cannot be separated linearly

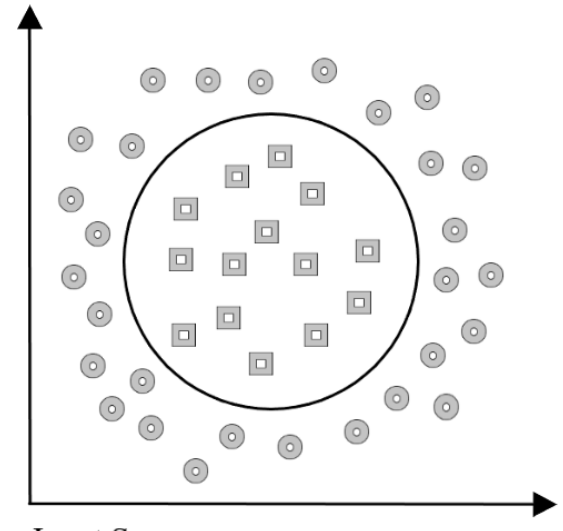

Input Space

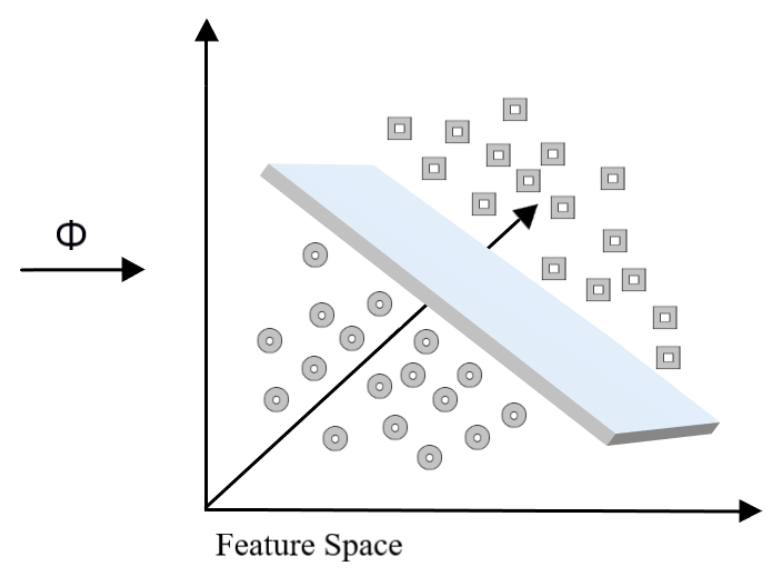

Figure 4. Classification in high dimensional space with kernel functions (Kavzoglu and Colkesen, 2009)

Table 1. Kernel function types

\begin{tabular}{lll}
\hline Kernel & Equation & Parameter \\
Linear & $\mathrm{K}(\mathrm{x}, \mathrm{y})=\mathrm{x} \cdot \mathrm{y}$ & - \\
Polynomial & $\mathrm{K}(\mathrm{x}, \mathrm{y})=((\mathrm{x} \cdot \mathrm{y})+1)^{\mathrm{d}}$ & $\mathrm{d}$ : Polynomial Degree \\
Radial Basis Function & $\mathrm{K}(\mathrm{x}, \mathrm{y})=\exp \left(-\boldsymbol{r}\left\|\left(\mathrm{x}-\mathrm{x}_{\mathrm{i}}\right)\right\|^{2}\right)$ & Y: Kernel Size \\
Sigmoid & $\mathrm{K}(\mathrm{x}, \mathrm{y})=\tanh (\mathrm{b}(\mathrm{x} \cdot \mathrm{y})+\mathrm{r})$ & $\mathrm{b}, \mathrm{r}$ : Kernel Parameters \\
\hline
\end{tabular}

When the hyper plane cannot be determined by linear equations, the data can be classified by extending into the property space with the Kernel functions as shown in Figure 4 (Kavzoglu and Colkesen, 2009).

Decision function as a result of applying SVM with Kernel functions

$\mathrm{f}(\mathrm{x})=\operatorname{sign}\left(\sum_{\mathrm{i}=1}^{\mathrm{n}} \lambda_{\mathrm{i}} \cdot \mathrm{y}_{\mathrm{i}} \cdot \Phi\left(\mathrm{x}_{\mathrm{i}}\right) \cdot \Phi\left(\mathrm{x}_{\mathrm{j}}\right)+\mathrm{b}\right)$

is expressed as (Kavzoglu and Colkesen, 2009).
As seen in Table 1, Kernel Functions used in SVMs can be examined in 4 groups (Colkesen and Kavzoglu, 2008).

SVM compared to traditional learning methods; it has started to be used frequently in terms of its advantages such as producing successful results, modeling complex boundaries, and working on a small amount of high data (Monter et al., 2005; Mountrakis et al., 2011). Also SVM; It appears to be more advantageous in terms of regression analysis, traditional machine learning 
methods, low convergence rate compared to other methods such as artificial neural networks, need for sufficient training data, less generalization rate, overfitting problem and adherence to local minimum ( $\mathrm{Lu}$, et al., 2002; Mountrakis et al., 2011).

\section{Digital Image Processing}

Arnavutkoy is located on the European side of the in Istanbul (Fig.5). The change of the land cover of Arnavutkoy between 1995-2019 was examined.

In this study, ArcMap 10.3 software (trial version) and ENVI 5.3 software (trial version) were used to create the necessary training data and classify using SVM algorithm. Working computer; it has Intel (R) Core (TM) i7-6500U CPU processor, 8.00 GB RAM and 64 bit operating system. 1995, 2005, 2010 Landsat 4-5; 2000 Landsat 7 and 2015, 2019 Landsat 8 OLI/TIRS satellite images were used in this study. A total of 4 bands $R, G$, $\mathrm{B}$ and NIR, were selected as data bands.

Five image processing steps were used (Fig.6). The maps obtained as a result of applying the steps followed in the application to Landsat data are as in Figure 7, Figure 8, Figure 9, Figure 10, Figure 11, Figure 12.
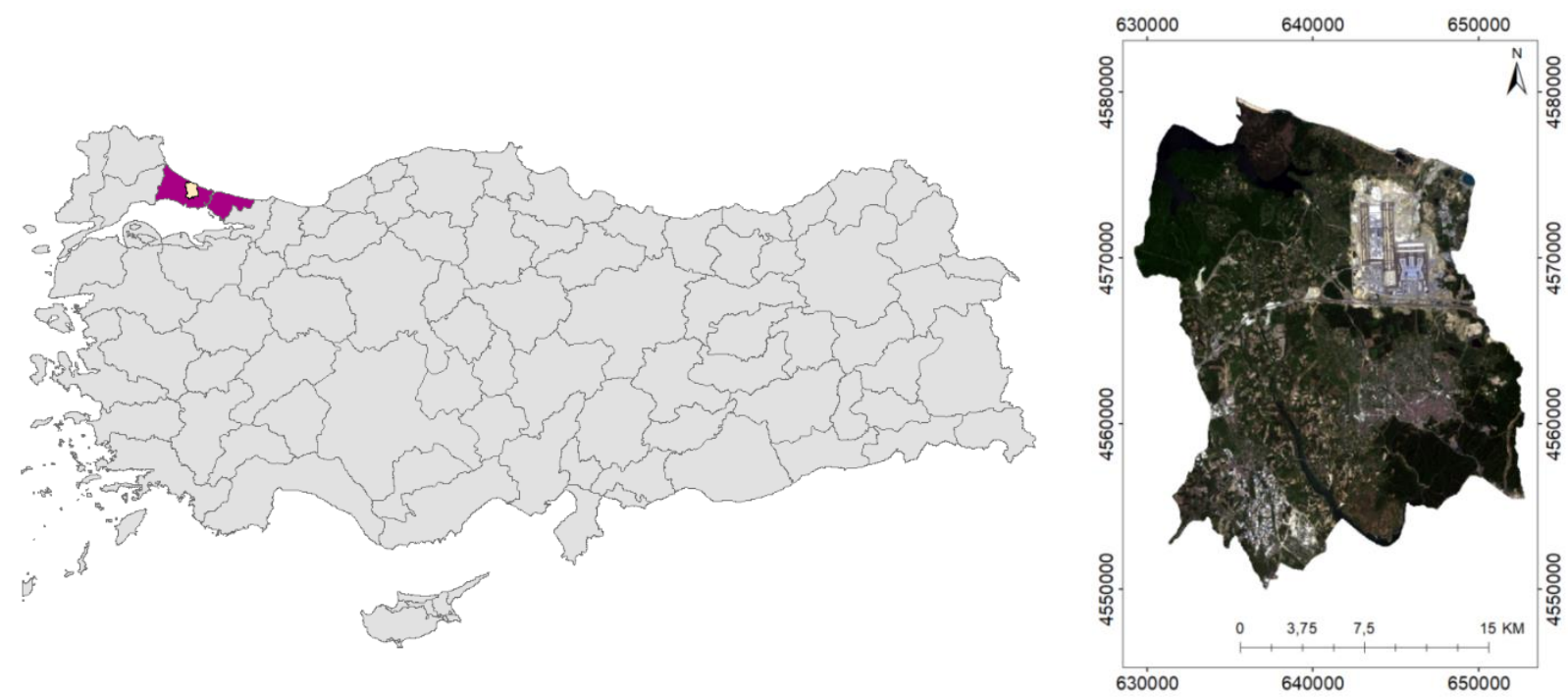

Figure 5. Study area

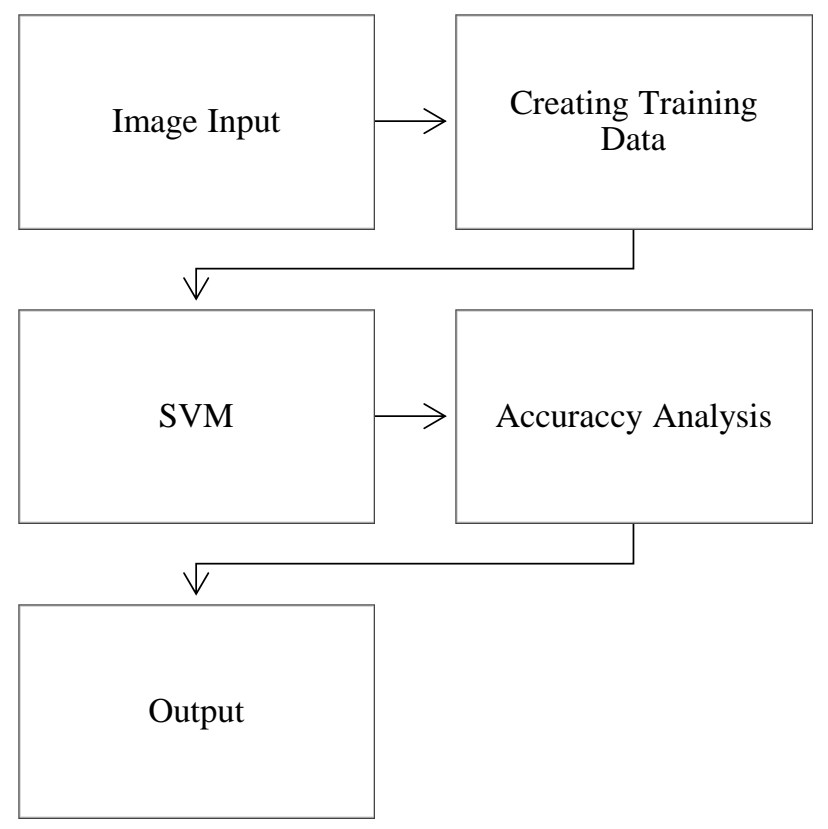

Figure 6. Study workflow 

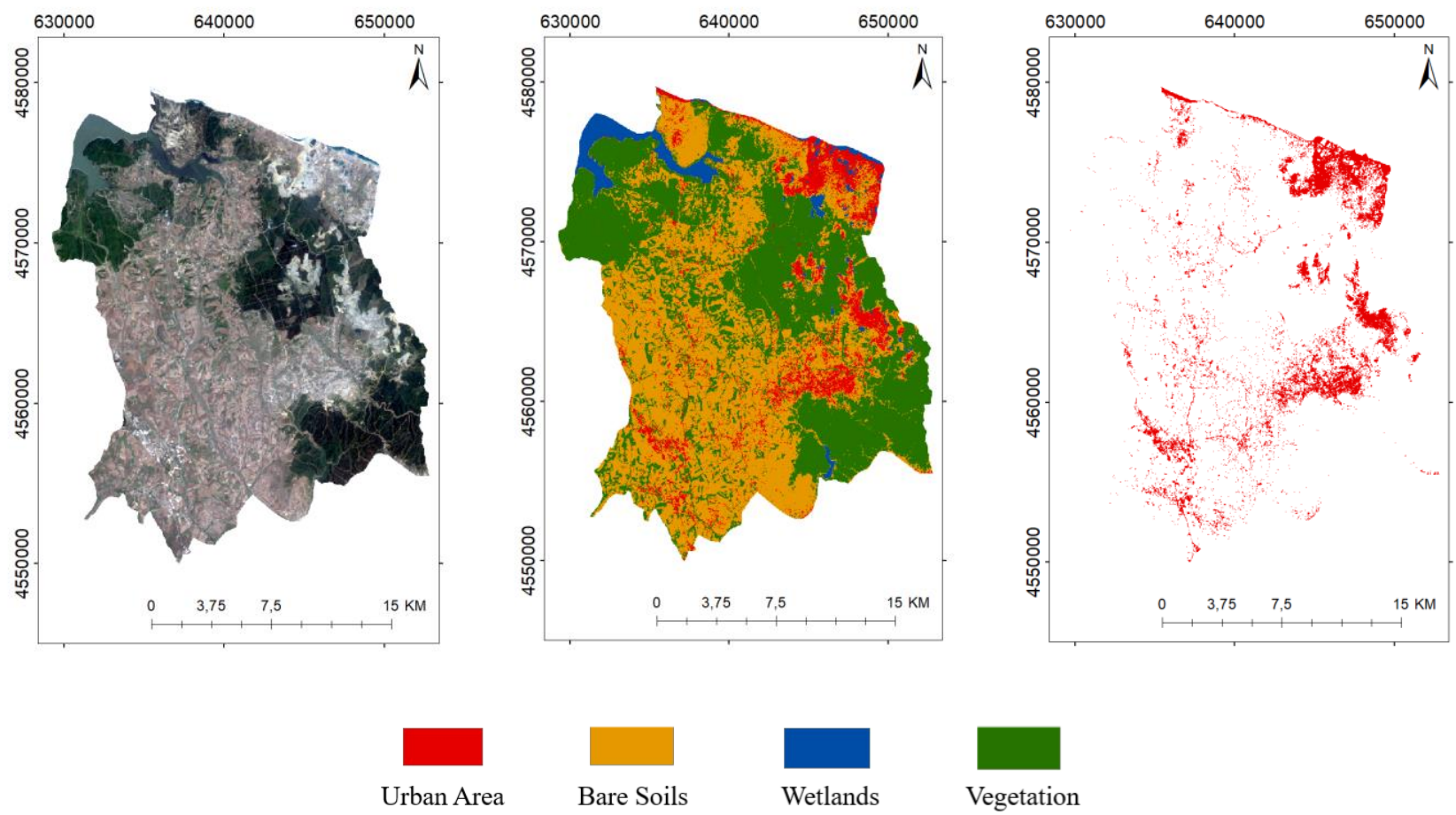

Figure 7. Raw data of Landsat 5-1995 (a), Image classification (b), Urban area obtained by classification (c).
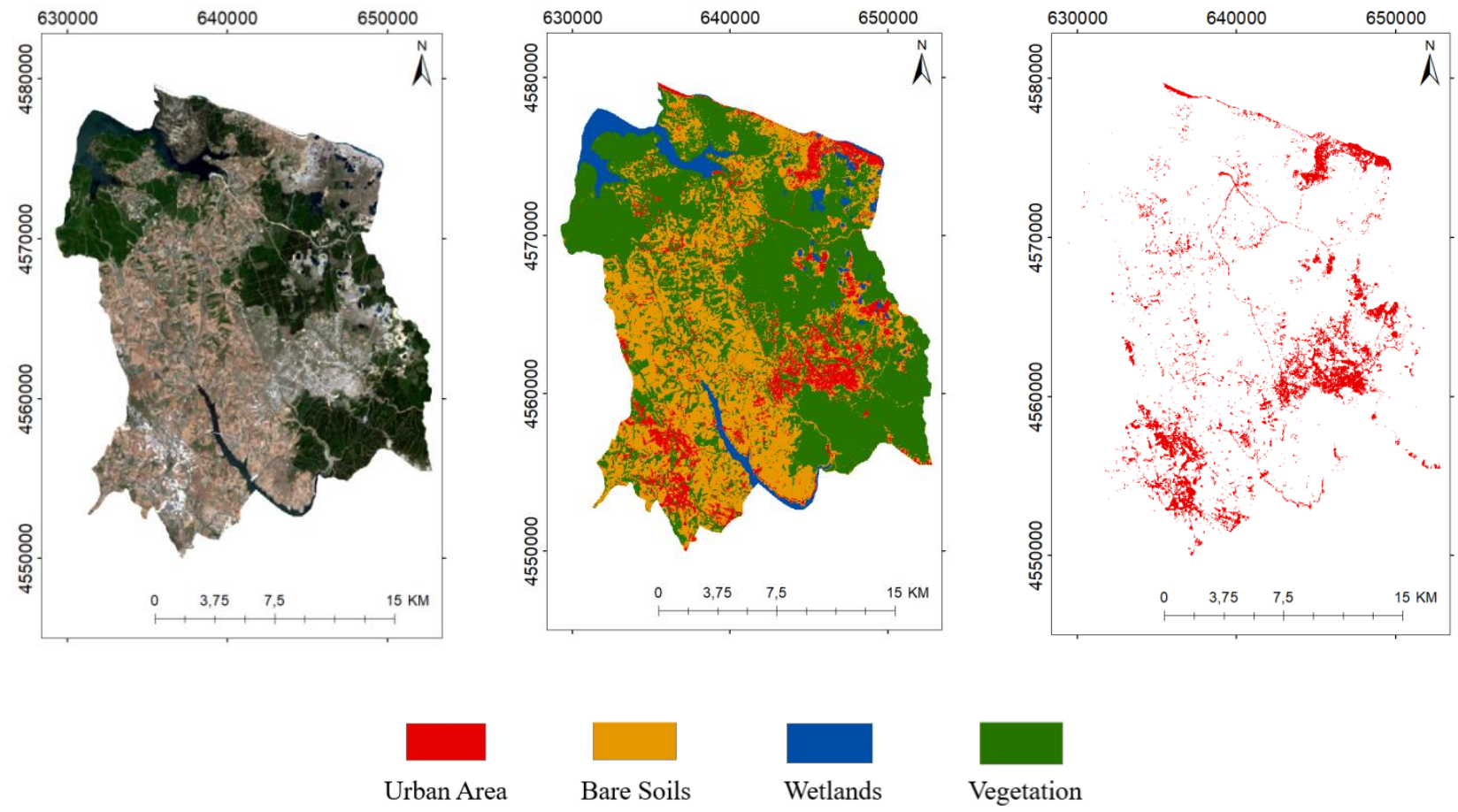

Figure 8. Raw data of Landsat 7-2000 (a), Image classification (b), Urban area obtained by classification (c) 

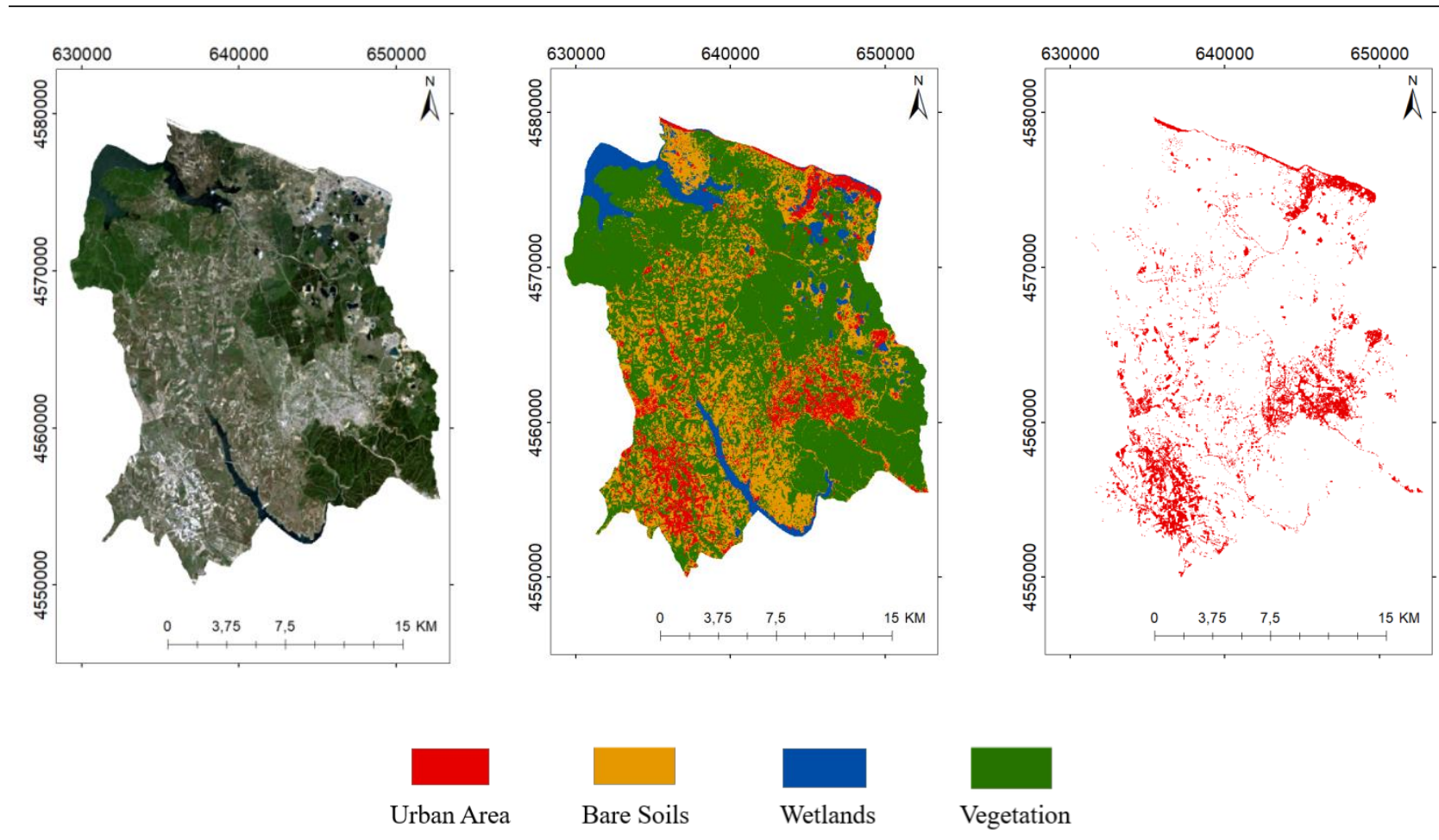

Figure 9. Raw data of Landsat 5-2005 (a), Image classification (b), Urban area obtained by classification (c)
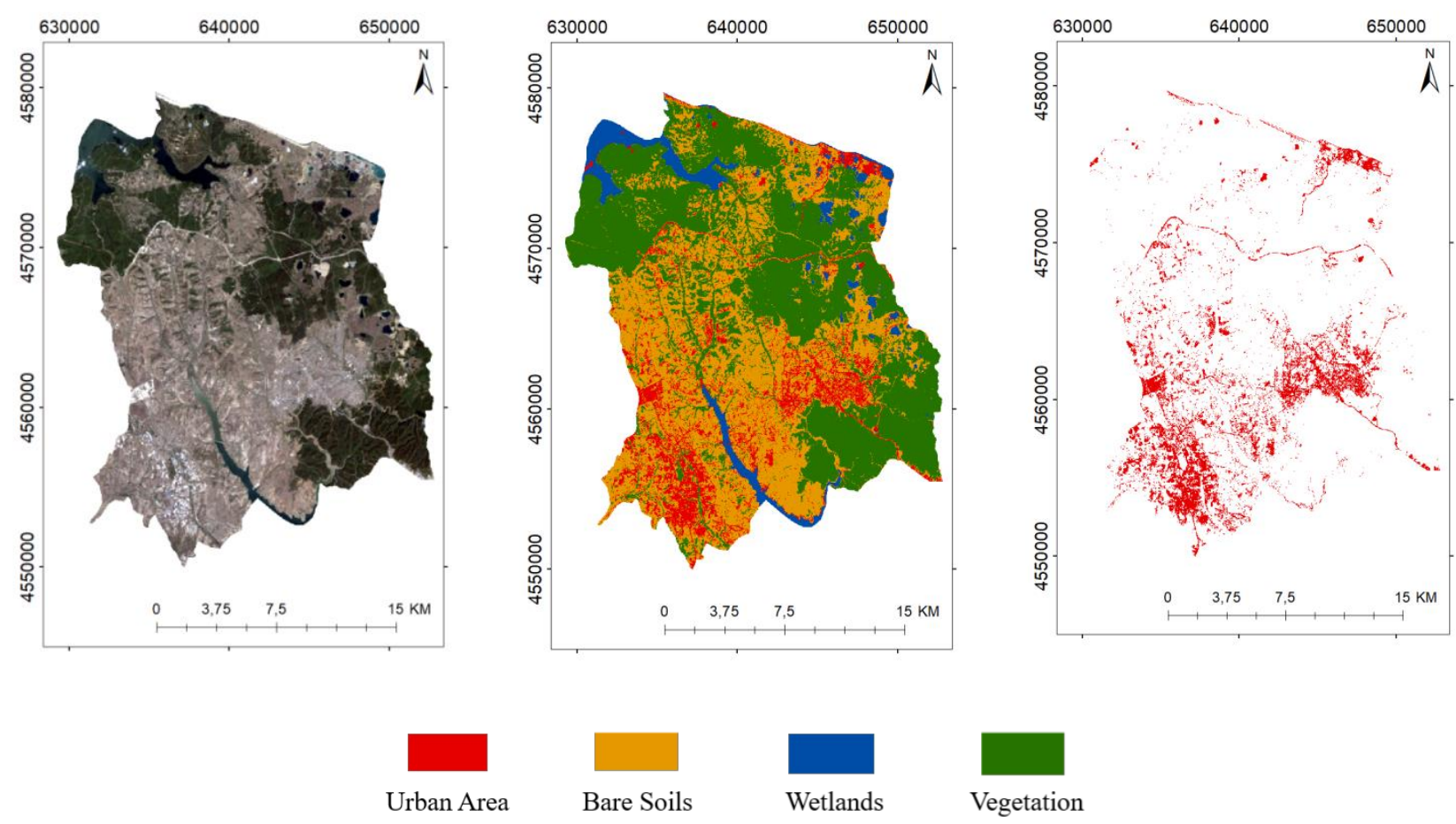

Figure 10. Raw data of Landsat 5-2010 (a), Image classification (b), Urban area obtained by classification (c) 

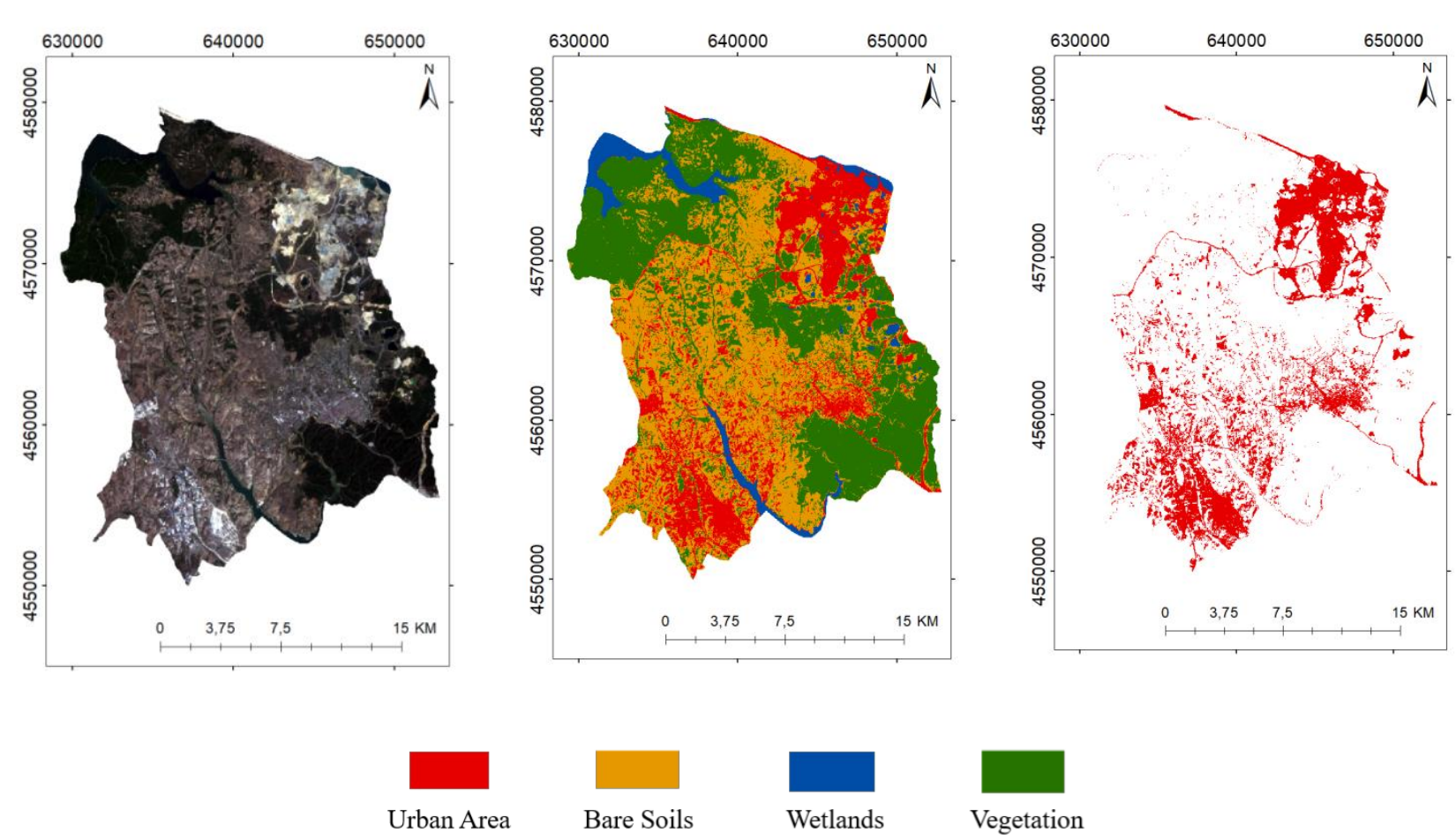

Figure 11. Raw data of Landsat 8-2015 (a), Image classification (b), Urban area obtained by classification (c)
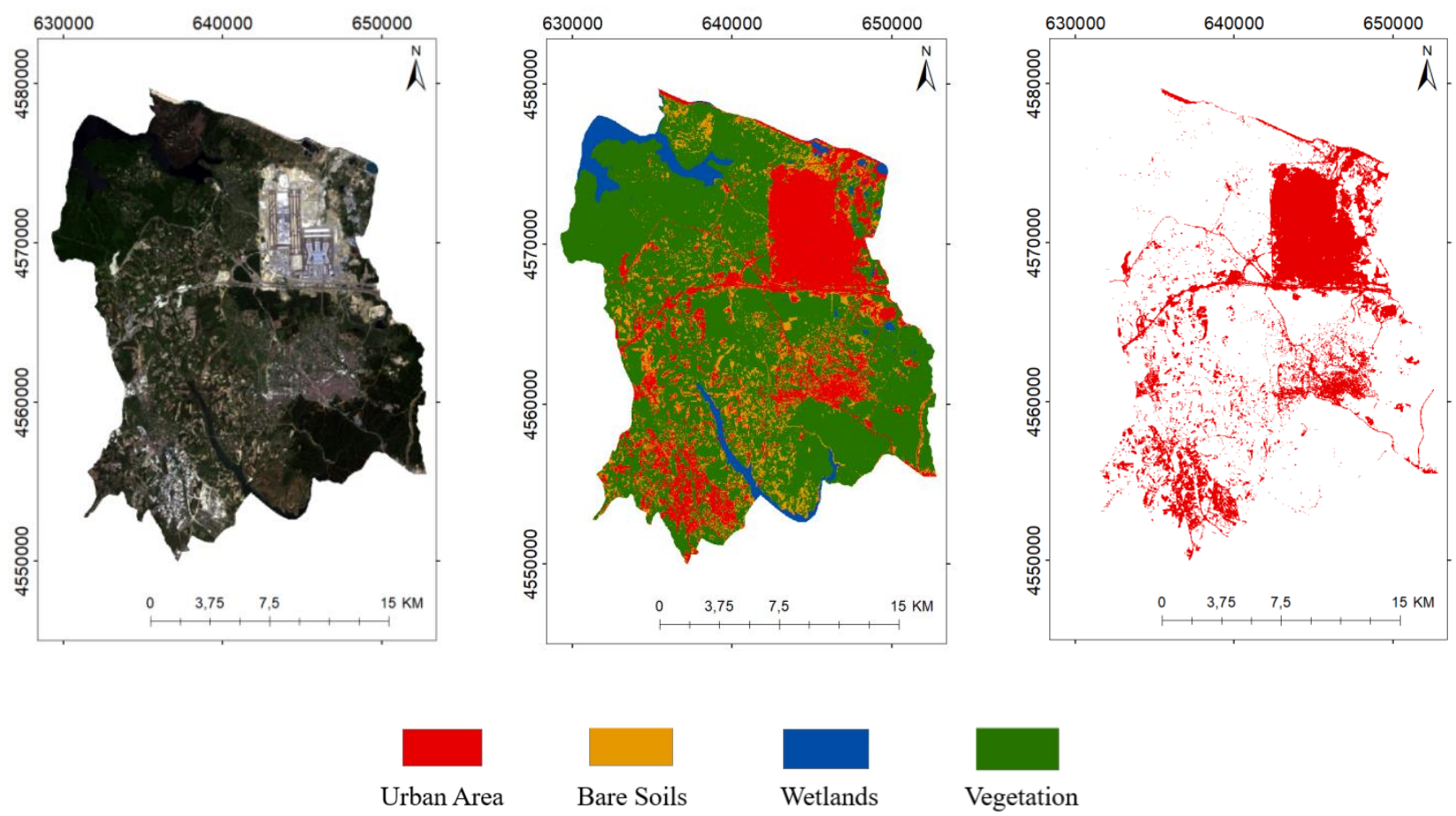

Figure 12. Raw data of Landsat 8-2019 (a), Image classification (b), Urban area obtained by classification (c) 


\section{Conclusion and Results}

Educational data for each satellite image obtained primarily in the study was created and classified with SVM. Afterwards, accuracy analysis was applied to the resulting maps.
Accuracy analyzes obtained from the data as a result of classification are shown in Table 2. In addition, the success/performance of the study was evaluated with accuracy and F criteria in ROC (Receiver Operator Characteristics Curve) analysis (Table 3). Values above $85 \%$ were considered excellent.

Table 2. Landsat images classification accuracy analysis

\begin{tabular}{lllll}
\multirow{2}{*}{ Years } & Accuracy of classes & & & \\
& Urban Area & Wetland & Bare Soils & Vegetation \\
\hline 1995 & $96.41 \%$ & $100.00 \%$ & $97.39 \%$ & $100.00 \%$ \\
2000 & $95.12 \%$ & $99.83 \%$ & $97.57 \%$ & $99.73 \%$ \\
2005 & $97.45 \%$ & $99.61 \%$ & $97.88 \%$ & $100.00 \%$ \\
2010 & $90.12 \%$ & $100.00 \%$ & $96.90 \%$ & $100.00 \%$ \\
2015 & $90.23 \%$ & $99.82 \%$ & $94.05 \%$ & $99.58 \%$ \\
\hline 2019 & $92.82 \%$ & $100.00 \%$ & $95.93 \%$ & $99.49 \%$ \\
\hline
\end{tabular}

Table 3. Accuracy analysis of methods

\begin{tabular}{|c|c|c|c|c|}
\hline Years & Accuracy & F-measure & Kappa Coefficient & Overall Accuracy \\
\hline 1995 & 0.986 & 1.000 & 0.982 & $98.66 \%$ \\
\hline 2000 & 0.983 & 0.990 & 0.977 & $98.31 \%$ \\
\hline 2005 & 0.989 & 0.990 & 0.985 & $98.95 \%$ \\
\hline 2010 & 0.98 & 1.000 & 0.971 & $97.99 \%$ \\
\hline 2015 & 0.963 & 0.990 & 0.951 & $96.37 \%$ \\
\hline 2019 & 0.979 & 1.000 & 0.971 & $97.90 \%$ \\
\hline
\end{tabular}

Temporal Change Graph

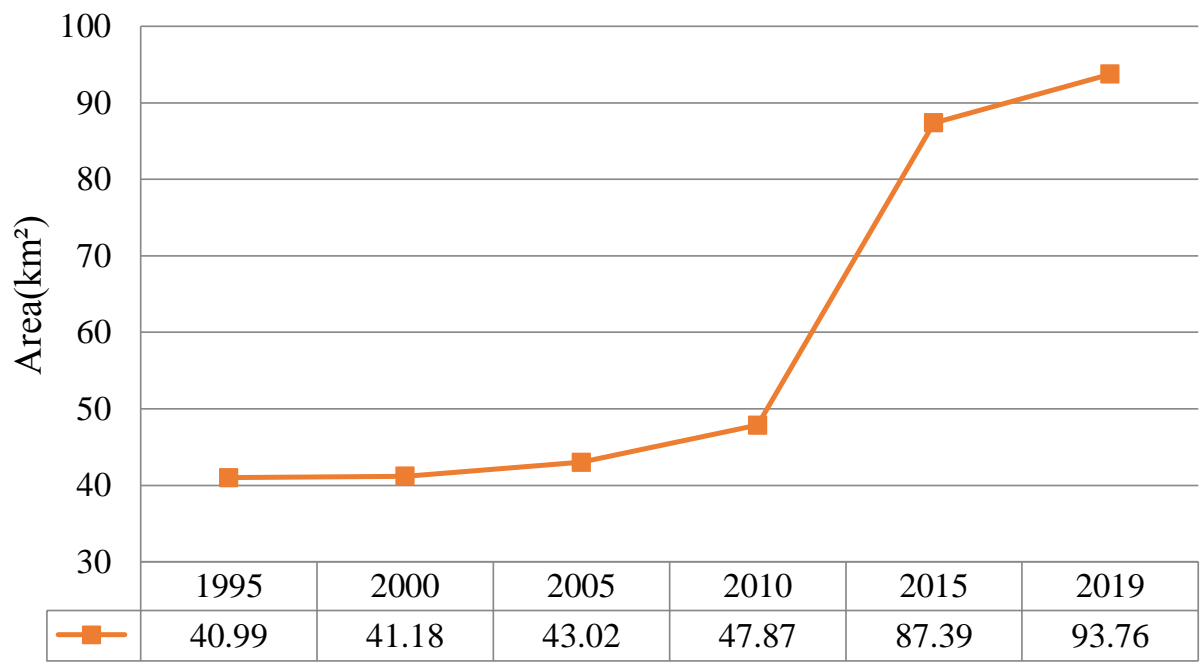

Figure 13. Temporal change graph 
There are many criteria that affect the classification accuracy. The most important of these criteria is the resolution of the data used. Another important criterion is the month in which the Landsat data used are obtained, the cloud ratio and the image error. These criteria affect classification accuracy positively or negatively. In the image preprocessing step, attention has been paid to selecting the images as close as possible and with the minimum cloud ratio. Therefore, seasonal conditions affected the application to a minimum. One of the biggest problems encountered in the study is the overlap of the created classes. In the urban area and bare soil classes, some pixels were in similar spectral range, causing the classes to mix with each other. As a result, accuracy decreases and errors occur in the classification created.

As a result of SVM application, the temporal change graph of urban areas obtained with the help of pixel values of each class is given in Figure 13.

As a result, it has been observed that using SVM to classify land cover/use gives high classification accuracy results. The algorithm has been shown to produce a good result in terms of success/performance for the Landsat data used in this application. It has been suggested that the SVM algorithm is used as an optimal classifier for land use/cover mapping and to investigate temporal change. Investigation of temporal change with SVM; it is anticipated that there may be a base for studies such as urban development/construction, natural disaster management, coastal line and study of vegetation change.

\section{References}

Bulut, S., Gunlu, A. (2016). Comparison of different supervised classification algorithms for land use classes (Turkish). Journal of Forestry Faculty, 16(2), 528-535.

Buyuksalih, I. (2016). Landsat images classification and change analysis of land cover/use. International Journal of Environment and Geoinformatics, 3(2), 56-65.

Colkesen, I., Kavzoglu, T. (2008). Classification of Land Cover Using Support Vector Machines: Gebze sample (Turkish). (s. 35-45). Kayseri: 2nd Remote Sensing and Geographical Information Systems Symposium.

Cortes, C., Vapnik, V. N. (1995). Support-Vector Network. Machine Learning, 20, 273-397.

Çelik, O., Gazioğlu, C. (2020). Coastline Difference Measurement (CDM) Method. International Journal of Environment and Geoinformatics, 7(1), 1-5.doi. 10.30897/ijegeo.706792.

Erdem, F., Avdan, U. (2020). Comparison of Different U-Net Models for Building Extraction from HighResolution Aerial Imagery, International Journal of Environment and Geoinformatics, 7(3), 221-227.doi. 10.30897/ijegeo.684951

Foody, G. M. (2002). Status of land cover classification accuracy assessment. Remote Sensing of Environment, 80, 185-201.
Heisele, B., Serre, T., Prentice, S., Poggio, T. (2003). Hierarchical classification and feature reduction for fast face detection with support vector machines. Pattern Recognition, 36, 2007-2017.

Hong, J., Min, J., Cho, U., Cho, S. (2008). Fingerprint classification using one-vs-all support vector machines dynamically ordered with naïve bayes classifiers. Pattern Recognition, 41, 662-671.

$\mathrm{Hu}$, X., Weng, Q. (2009). Estimating impervious surfaces from medium spatial resolution imagery using the self-organizing map and multi-layer perceptron neural networks. Remote Sensing of Environment, 113, 2089-2102.

Huang, C., Davis, L. S., Townshend, J. R. (2002). An assessment of support vector machines for land cover classification. International Journal Remote Sensing, 23(4), 725-749.

Jamsran, B. E., Lin, C., Byambakhuu, I., Raash, J., Akhmadi, K. (2019). Applying a support vector model to assess land cover changes in the Uvs Lake basin ecoregion in mongolia. Information Processing in Agriculture, 6, 158-169.

Joachims, T. (1998). Text Categorization with Support Vector Machines: learning with Many Relevant Features. In Proceedings of European Conference on Machine Learning, (s. 137-142).

Karagöl, S., Bayram, B., Erdem, F., Bakırman, T. (2020). Aktarımlı Öğrenme ile SENTINEL-2 Görüntülerinden Kıyı Çizgisi Bölütlemesi, Türkiye Uzaktan Algllama Dergisi - 2020; 1(1); 00-OX

Karimi, F., Sultana, S., Babakan, A. S., Suthaharan, S. (2019). An enhanced support vector machine model for urban expansion prediction. Computers, Environment and Urban Systems, 75, 61-75.

Kavzoglu, T., Colkesen, I. (2009). A kernel functions analysis for support vector machines for land cover classification. International Journal of Applied Earth Observation and Geoinformation, 11, 352-359.

Kavzoglu, T., Colkesen, I. (2010). Classification of Satellite Images Using Decision Trees: Kocaeli Case. Electronic Journal of Map Technologies, 2(1), 36-45.

Keerthi, S. S., Lin, C. J. (2003). Asymptotic behaviors of support vector machines with Gaussian kernel. Neural Computation, 15, 1667-1689.

Liu, C., Nakashima, K., Sako, H., Fujisawa, H. (2003). Handwritten digit recognition: benchmarking of state-of-the-art techniques. Pattern Recognition, 36, 2271-2285.

Lu, D., Weng, Q. (2007). A survey of image classification methods and techniques for improving classification performance. International Journal of Remote Sensing, 28(5), 823-870.

Lu, W., Wang, W., Leung, A. T., Lo, S., Yuen, R. K., $\mathrm{Xu}, \mathrm{Z}$., et al. (2002). Air pollutant parameter forecasting using support vector machines. (s. 630635). Honolulu: Proceedings of the 2002 International Joint Conference on Neural Networks. IJCNN'02.

Mathur, A., Foody, G. M. (2008). Crop classification by support vector machine with intelligently selected training data for an operational application. 
International Journal of Remote Sensing, 29, 22272240.

Melgani, F., Bruzzone, L. (2004). Classification of hyperspectral remote sensing images with support vector machines. IEEE transactions on geoscience and remote sensing, 42(8), 1778-1790.

Mohapatra, R. P., Wu, C. (2010). High resolution impervious surface estimation: an integration of Ikonos and Landsat-7 ETM+ imagery. Photogrammetric Engineering Remote Sensing, 76(12), 1329-1341.

Montero, P., Moser, G., Serpico, S. B. (2005). Partially supervised classification of remote sensing images through SVM-based probability density estimation. IEEE Transactions on geoscience and remote sensing, 43(3), 559-570.

Mountrakis, G., Im, J., Ogelo, C. (2011). Support vector machines in remote sensing: A review. ISPRS Journal of Photogrammetry and Remote Sensing, 66, 247-259.

Nagel, P., Yuan, F. (2016). High-resolution land cover and impervious surface classifications in the twin cities metropolitan area with NAIP imagery. Photogrammetric Engineering Remote Sensing, 82(1), 63-71.

Nemmour, H., Chibani, Y. (2006). Multiple support vector machines for land cover change detection: an application for mapping urban extensions. Photogrammetry Remote Sensing, 61, 125-133.

Osuna, E. E., Freund, R., Girosi, F. (1997). Support Vector Machines: Training and Applications. Massachusetts: A.I. Memo No. 1602, C.B.C.L. Paper No. 144, Massachusetts Institute of Technology Artificial Intelligence Laboratory and Center for Biological and Computational Learning Department of Brain and Cognitive Sciences.

Ozturk, O., Sarıtürk, B., Seker, D. (2020). Comparison of Fully Convolutional Networks (FCN) and U-Net for Road Segmentation from High Resolution Imageries, International Journal of Environment and Geoinformatics, 7(3), 272-279.doi. 10.30897 lijegeo.737993

Petropoulos, G. P., Arvanitis, K., Sigrimis, N. (2012b). Hyperion hyperspectral imagery analysis combined with machine learning classifiers for land use/cover mapping. Expert Systems with Applications, 39, 3800-3809.

Petropoulos, G. P., Kalaitzidis, C., Vadrevu, K. P. (2012a). Support vector machines and object-based classification for obtaining land-use/cover cartography from hyperion hyperspectral imagery. Computers Geosciences, 41, 99-107.

Serifoglu Yilmaz, C., Gungor, O., Kahraman, H. T. (2018). Land cover mapping with advanced classification algorithms. Nature Sciences, 13(3), 4150.

Song, X., Duan, Z., Jiang, X. (2012). Comparison of artificial neural networks and support vector machine classifiers for land cover classification in Northern China using a SPOT-5 HRG image. International Journal of Remote Sensing, 33(10), 3301-3320.

Tonbul, H., Kavzoglu, T. (2020). A Spectral Band Based Comparison of Unsupervised Segmentation
Evaluation Methods for Image Segmentation Parameter Optimization, International Journal of Environment and Geoinformatics, 7(2), 132139.doi.10.30897/ijegeo.641216

Ustuner, M., Balik Sanli, F. (2020). Crop classification using multi-temporal polarimetric SAR data (Turkish). Journal of Geodesy and Geoinformation, $1-10$.

Vapnik, V. N. (1995). The Nature of Statistical Learning Theory. New York: Springer-Verlag.

Vapnik, V. N. (2000). The Nature of Statistical Learning Theory, Second Edition. New York: Springer-Verlag.

Zhang, L., Zhang, M., Yao, Y. (2018). Mapping seasonal impervious surface dynamics in Wuhan urban agglomeration, China from 2000 to 2016. International Journal Applied Earth Observation Geoinformation, 70, 63-71. 